\title{
Environmental Economic Dispatch with the Use of Particle Swarm Optimization Technique Based on Space Reduction Strategy
}

\author{
T. Manoj Kumar \\ Department of Electrical and Electronics Engineering, \\ Saveetha School Of Engineering, SIMATS, Chennai, India \\ manojkumart99@gmail.com
}

\author{
N. Albert Singh \\ Bharat Sanchar Nigam Limited \\ Chennai, India \\ basisngc@gmail.com
}

\begin{abstract}
This paper introduces a professional edition of Particle Swarm Optimization (PSO) technique, intending to address the Environmental Economic Dispatch problem of thermal electric power units. Space Reduction (SR) strategy based PSO is proposed, in order to obtain the Pareto optimal solution in the prescribed search space, by enhancing the speed of the optimization process. PSO is a natural algorithm, which can be used in a wide area of engineering issues. Many papers have illustrated different techniques that solve various types of dispatch problems, with numerous pollutants as constraints. Search SR strategy is applied to PSO algorithm in order to increase the particles' moving behavior, by using effectively the search space, and thus increasing the convergence rate, so as to attain the Pareto optimal solution. The validation of SR-PSO algorithm is demonstrated, through its application on an Indian system with 6 generators and three IEEE systems with 30,57 and 118 buses respectively, for variable load demands. The minimum fuel cost and least emission solutions are achieved by examining various load conditions.
\end{abstract}

Keywords-search space reduction; Particle Swarm Optimization (PSO); Environmental/Economic Dispatch (EED) problem; Pareto optimal solution

\section{INTRODUCTION}

The process of satisfying energy demands raises concerns regarding to energy durability and environmental protection, in conjunction with the market and regulatory demands. Environmental/Economic electricity Dispatch (EED) is a technique to plan the energy generator unit's output with load demand. EED is essential to create sufficient capacity in order to meet consistently variable client load demands at minimal cost under various difficulties. The EED problem is nonlinear, discontinuous and multimodal. It is essential to deliver power, generated by several units on an optimum current economic climate basis in order to attain the best results in the generating system. Many methods have been used to solve the dispatch. In [1] the Modulated Particle Swarm Optimization (MPSO) technique was presented to solve the EED problem of thermal units, modulating particles' velocity for better exploration and exploitation of search space. This modulation of velocity is controlled by introducing a sinusoidal constraint function in the control equation. A Fuzzified Multi-Objective Particle Swarm
Optimization (FMOPSO) algorithm was proposed in [2] where, in order to validate the effectiveness of the proposed method, a comparative study was conducted with other techniques, like Weighted Aggregation (WA) and Multi-Objective Evolutionary Algorithm (MOEA). Many further issues are to be considered, such as the nonlinear characteristics of ramp rate limits and the prohibited operating zones of power system operations. In [3] a new Strength Pareto Evolutionary Algorithm (SPEA) was proposed in order to compete with nonlinear objectives. Diversity preserving mechanism has been developed to resolve the Pareto optimal issue. An Artificial Bee Colony, improved with Dynamic Population size (ABCDP), has been introduced in [4], to prove the efficiency and effectiveness in handling the nonlinear multi-objective function. In [5], a modified Bacterial Foraging Algorithm (MBFA) was developed for the solution of the EED problem, using the global optimum bacterium having successful foraging strategy. This method shows the capability of obtaining quality compromise solution and the operator has to decide different objectives according to system constraints. Another method of the hybrid multi-objective algorithm based on Particle Swarm Optimization (PSO) and Differential Evolution (DE) was proposed in [6], where the search space is completely explored by the PSO, while DE takes the initiative in exploiting the subspace with sparse solutions. In this approach, the exploration and exploitation capability has been improved by the effective usage of crowding distance and time variant acceleration coefficients.

A new Multi-Objective Particle Swarm Optimization (MOPSO) that resolves the EED issue is explained in [7]. This technique is the multi-objective version of PSO, offering the redefinition of global and local best individuals in search space. The potential and efficiency of this method is proved by obtaining multiple optimal solutions in one simulation run and validating the diversity and well-distributed characteristics of the non-dominated solutions. A flower pollination technique, used to resolve the Economic Load Dispatch (ELD) and Combined Economic and Emission Dispatch (CEED) problems is suggested in [8]. Simulation results were compared to other swarm based techniques to show its effectiveness. Its main advantage is that it can be used for large-scale power systems 
with valve-point effects. Many parameters were checked such as converging property, computational efficiency, and economic effect. Spiral Optimization Algorithm (SOA) is used in [9], to resolve the economic and emission dispatch problem, in order to obtain minimum fuel cost and emanation level, while satisfying the required load demand and operational constraints. This is a metaheuristic optimization algorithm having several advantages, including its few control variables, local searching capability, fast results, easy using process and simple structure. The Multi-Objective Differential Evolution (MODE) algorithm is described in [10] to resolve the EED problem. Crowding entropy diversity tactic is used in order to preserve the diversity of Pareto optimal solution. Also, fuzzy set theory is employed to extract the best compromise between fuel cost and emission. A stochastic PSO method was used in [11], by formulating both deterministic and stochastic models to deal with the economic load dispatch problem, considering the environmental impacts as constraints. In [12] a Niched Pareto Genetic Algorithm (NPGA) approach is presented, considering the whole EED problem as a multi-objective issue, with total fuel cost and emissions as competing objective functions. The main advantage of this method is that there is no restriction on the number of objectives to optimize. FPA is explained in [13], where only fuel cost is considered as the objective function to resolve the ELD problem, while both fuel cost and emissions are considered for CEED. The superiority of FPA to other algorithms is discussed, even for a large power system with valve-point effects. A nonlinear fractional approach for resolving the EED is elaborated in [14], presenting two simultaneous models of objective functions with nonlinear constraints. The first model minimizes the quotient of fuel cost and emission function, while the latter minimizes the total fuel cost expressed as a quadratic objective function. The Non-dominated Sorting Genetic Algorithm (NSGA-II) faces many drawbacks, such as lack of uniform diversity and absence of lateral diversity. These can be eliminated by introducing Dynamic Crowding Distance (DCD), using a modified NSGA-II algorithm [15]. Differential Evolution (DE) algorithm is developed with emission constrained economic dispatch problem in [16], to minimize the fuel cost. But due to the heavy environmental impact created by the thermal power plants, it has to be considered as an additional objective function.

The innovative Tribe-Modified Differentia Evolution (Tribe-MDE) is presented in [17] to solve the multi-objective EED problem. This multi-objective problem can be altered into a min-max problem, in order to be resolved with the TribeMDE algorithm. A bare-bones multi-objective PSO algorithm to resolve the EED issue is presented in [18]. Several advantages are reported here, such as particle updating strategy without tuning procedures and mutation operation, with expanded search capability. The Time-Varying Acceleration based PSO (PSO-TVAC) technique is proposed in [22] to resolve the EED problem. The standard PSO algorithm can be improved by adjusting the acceleration constant in order to get a balanced exploration and exploitation capability. In [24], the exact method to resolve the EED problem and PSO to get the Pareto optimal solution is elaborated. In [25], different evolutionary algorithms are applied to solve EED problems in various electrical power systems, comparing their performance. Resolving the economic dispatch problem by an improved version of the random drift PSO algorithm is explained in [26]. In [27], an improved PSO, called Biogeography-based Learning Particle Swarm Optimization (BLPSO), is presented for solving the ED problems involving different constraints. The chaotic bat algorithm is deployed in [28] for solving the ED problem, involving equality and inequality constraints such as power balance, prohibited operating zones, and ramp rate limits. An improved differential evolution algorithm for the ELD problem, with or without valve-point effects, is explained in [29]. An adaptive PSO with heterogeneous multicore parallelism and GPU acceleration is deployed in [30], while new swarm intelligence is applied in [32]. In [31], the resolution of multi-objective EED problem by utilizing the Grey Wolf optimization algorithm is explained, analyzing various operating constraints. A new optimization technique named Elephant Herd Optimization (EHO) was proposed in [33], for global optimization. Like most different metaheuristic algorithms, EHO is not using the preceding individuals inside the later updating process. In [34], a combined heat and power economic dispatch problem is resolved, utilizing an advanced modified PSO technique on different systems. In [35], a TLABC algorithm is proposed, which employs three hybrid search stages, in its search for the optimization parameters.

The primary purpose of this study is to present the utilization of Space Reduction Particle Swarm Optimization (SR-PSO) optimization technique in power systems. SR-PSO is a versatile and well-balanced mechanism that improves exploration and exploitation. The SR-PSO method is proposed to resolve environmental/economic dispatch (EED) problems for different power systems, such as an Indian Utility System having 6 units, and three IEEE systems with 30, 57 and 118 buses respectively. Results are studied comparatively with other researches from the relevant literature.

\section{PROBLEM FORMULATION}

In order to resolve the EED problem, we should examine the best mixture of power generation that diminishes the aggregate cost, by considering fuel and emission expenditure, under numerous working conditions. The multi-objective advancement technique is commonly used to get the ideal solution for real-world challenges. The main objectives are:

- Minimization of fuel cost: In a power system with $\mathrm{N}$ number of generators, the total fuel price can be determined by:

$$
F\left(p_{g}\right)=\sum_{i=0}^{N} F_{i}\left(P_{i}\right)=\sum_{i=1}^{N} a_{i} P_{i}^{2}+b_{i} P_{i}+c_{i}
$$

where $F\left(p_{g}\right)$ denotes the total generation fuel cost, $P_{i}$ represents the electrical output of $i^{\text {th }}$ generator, $a_{i}, b_{i}$ and $c_{i}$ signify the cost coefficients of $i^{\text {th }}$ generator and $N$ denotes the quantity of generators assigned to the operating system

- Minimization of emissions: Total emissions with fossil gas based heat generation are given by:

$$
E\left(p_{g}\right)=\sum_{i=0}^{N} E_{i}\left(P_{i}\right)=\sum_{i=1}^{N} \alpha_{i} P_{i}^{2}+\beta_{i} P_{i}+\gamma_{i}
$$


where $E\left(p_{g}\right)$ denotes total emissions and $a_{i}, \beta_{i}$ and $\gamma_{i}$ are the emission coefficients of the $i^{t h}$ unit.

The multi-objective search engine optimization problem offers two goals, economy and emissions. It is transformed into a solitary objective search engine optimization problem as:

$$
T\left(p_{g}\right)=u * F\left(P_{g}\right)+(1-u) E\left(P_{g}\right)
$$

where $T$ is total cost and $0<u<1$ is a compromising factor. When $u$ is zero, the aim function is only emission dispatch problem which limits the emissions of the plant. When $u$ is 1 , the objective function becomes entirely a conventional economical load dispatch problem, which restricts the availability expenses of this scheme.

EED problem has two constraints. Firstly, there are the generator's constraints, as the real power productivity of every generator will be in the middle of its base, while optimum limits and the inequality constraints for every generator must be assured:

$$
P_{g i}^{\min } \leq P_{g i} \leq P_{g i}^{\max }, i=1, \ldots . . N
$$

where $P_{g i}^{\min }$ and $P_{g i}^{\max }$ are the lower and upper limits of power of the $i^{\text {th }}$ unit. Secondly, there are the power balance constraints, where the aggregate power loss has the real power reduction in transmission line $P_{L}$ and total demand $P_{D}$. Then:

$$
\sum_{i=1} P_{g i}-P_{D}-P_{L}=0
$$

in which the system loss function $P_{L}$ is given by:

$$
P_{L}=\sum_{i=1}^{N} \sum_{j=1}^{N}\left(P_{i} B_{i j} P_{j}\right) M W
$$

\section{SR-PSO IMPLEMENTATION IN THE EED PROBLEM}

Inspired by the social behavior of animals like bird flocking, fish schooling and swarm basic principle, PSO is broadly utilized for the resolution of the heavily limited EED problem. The particles move throughout the multi-dimensional search space till they discover the optimal solution. By their own knowledge $\left(P^{\text {best }}\right.$ ) and the knowledge achieved by nearest particles $\left(G^{\text {best }}\right)$, every particle updates its situation throughout the flight. Velocity and position of the $i^{\text {th }}$ particle, for fitness evaluation at $(k+1)$ iteration in $m$-dimensional search space, are given by:

$$
\begin{gathered}
V_{i}^{k+1}=w \cdot V_{i}^{k}+c_{1} \cdot r_{1} \cdot\left(P_{\text {best }_{i}}-x_{i}^{k}\right)+c_{2} \cdot r_{2} \cdot\left(G_{\text {best }_{g}}-x_{i}^{k}\right) \\
P_{i}^{k+1}=P_{i}^{k}+V_{i}^{k+1}, \quad V_{i}^{k=0}=0
\end{gathered}
$$

where, $i$ is particle's index, $k$ represents the discrete time index, $n$ denotes the number of particles in a group, $m$ signify the dimensions of a particle, $\mathrm{W}$ is the inertia weight factor, $P_{i}^{\text {best }}$ represents the best position found by $i^{\text {th }}$ particle , $G_{i}^{\text {best }}$ symbolizes the best position create by swarm, $c_{1}, c_{2}$ symbolize the acceleration coefficients, $r_{1}, r_{2}$ represent the uniform random values in the array $[0,1], P_{i}^{k}$ and $V_{i}^{k}$ indicate the position and velocity of the $i^{\text {th }}$ particle at $\mathrm{k}^{\text {th }}$ iteration.
A new strategy of the PSO algorithm is introduced for solving EED problems. Indicators will be addressed about how to handle the inequality and equality constraints of the EED complications, when adjusting every search point in PSO. A new method of PSO with SR strategy based optimization technique is used in order to improve the convergence rate of the process. This approach is activated, when the performance is not increased throughout a pre-specified time. In this method, the search space can be regulated with the proper usage of constant $\Delta$. The distance between the global best and maximum or minimum values of position values are added or subtracted with that constant, giving:

$$
\begin{aligned}
& P_{i \text { max }}^{k+1}=P_{i \text { max }}^{k}-\left(P_{i \text { max }}^{k}-\text { Gbest }_{i}^{k}\right) \Delta \\
& P_{i \text { min }}^{k+1}=P_{i \text { min }}^{k}+\left(P_{i \text { min }}^{k}-\text { Gest }_{i}^{k}\right) \Delta
\end{aligned}
$$

\section{A. Updating the Inertia Weight}

The update of inertia weight is essential for resolving optimization problems. For high level optimization problems, a local optimum exists which is close to global optimum solutions. Consequently, the utilization capability of the search algorithm should be adequate to acquire the best solutions. Hence, the update of inertia weight is essential during the iteration process. This has to be done according to cycles. The up gradation of inertia weight is given below:

$$
w=\exp \left(-\eta \log _{e}\left(\frac{w_{\max }}{w_{\min }}\right)\right) ; \eta=\frac{i t r}{i t r_{\max }}
$$

\section{B. Updating the Position and Velocity of Particles}

The perceptive manners are taken into consideration, regarding the best and worst experience of particles in the given search space. Consequently, the idea of preceding knowledge of position and velocity of each particle is recommended, if the present fitness of every particle is weighted against its fitness value. If this value is small, then it can be treated as its experience. This particle's occurrence generates significantly less variety compared to worst experience and affords enhanced exploration and exploitation of space without utilizing supplementary regional random exploration.

\section{Formulating the Objective Function}

Numerous objectives are certainly converted into one, by simply pre-multiplying the excess weight supplied by the customer, with all targets, by utilizing weighted sum approach. The weights are usually picked in such a method that each one provides comparable importance for the problem. Usually weights happen to be preferred in such a way that their arithmetical sum is normally equal to one. The EED problem is represented as:

$$
F_{t}=u * F \cos t_{i}+(1-u) * E \cos t_{i}
$$

Every single objective function takes any kind of value within the array and $u$ is the weighting factor which decides the change of pressure over every objective function. The weighting factor $u$ can take distinct values between 0 and 1 . Equal chances to reduce both objective functions can be 
acquired when $w$ is located to 0.5 , where equal weight is set to both objective functions. An array of several solutions is usually obtained, known as Pareto optimal alternatives.

\section{Algorithm of the Proposed Method}

The implementation of SR-PSO in EED problem consists of the following steps: i) Initialization, setting the initial velocity to zero and randomizing particles' position. ii) Position upgrade, where every particle's position and velocity are updated, by considering the corresponding constraints. iii) Fitness value calculation, for all particles. iv) Obtain $P^{\text {best }}$, $G^{\text {best }}$ and thereafter save the corresponding positions. v) Use the proposed strategy based on space reduction. vi) Go to step (ii) until the required criterion is obtained. Here the optimization problem has the equality and inequality constraints explained before. Equality constraints indicate a problem to random optimization algorithms, though it is tough to meet up with the optimization procedure. Here constraints are managed as follows:

\section{1) Equality Constraints}

A new system is suggested to tackle this constraint in the EED issue. At all iterations, (3) is contented above.

i) Initially disregard the network losses and then randomly generate almost all units' power levels $P_{1}+P_{2}+\ldots \ldots \ldots \ldots+P_{N-1}$

ii) Determine the end unit's power level using (10)

iii) Determine the transmission losses by utilizing (6)

iv) Include losses into power by regulating the last unit's power level as:

$$
P_{N}=P_{D}-\left(P_{1}+P_{2}+\ldots \ldots+P_{N-1}\right)
$$

\section{2) Inequality Constraints}

Lower and upper power limits are checked after each iteration to make sure they concur with (4). If a particle flies out of limits, the current position shall be upgraded to the prior best position $\left(P^{\text {best }}\right)$. Figure 1 demonstrates the flowchart of the suggested SR-PSO technique. The cognitive and the social element in this algorithm have no constants. The position and velocity of the $i^{\text {th }}$ particle can be calculated using the following equations:

$$
\begin{aligned}
& v(k+1)=W * V(k)+\left(C_{1} * \text { rand } 1 *\left(p_{i}-x(k)\right)\right. \\
& +\left(C_{2} * \text { rand } 2 *\left(P_{b}-x(k)\right)\right. \\
& x(k+1)=x(k)+v(k+1) \\
& C_{1}=\left(\left(C_{1 f}-C_{1 i}\right) * \text { iter } / \text { iter }_{\max }+C_{1 i}\right) \\
& C_{2}=\left(\left(C_{2 f}-C_{2 i}\right) * \text { iter }_{\text {iter }}+C_{2 i}\right)
\end{aligned}
$$

where iter $_{\max }$ is the maximum iteration number and the inertia weight limits are between 0.4 and 0.9. $C_{1 i}, C_{2 i}, C_{1 f}$, and $C_{2 f}$ denote the initial and the final values for cognitive and social factors, while $C_{1}$ and $C_{2}$ represent the cognitive and social factors respectively.

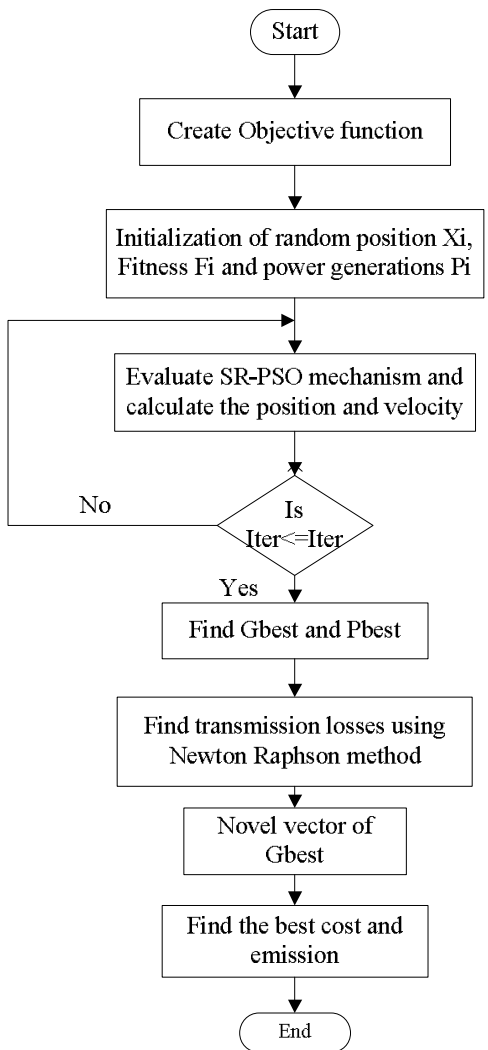

Fig. 1. Flowchart for the proposed SR-PSO EED problem resolution

\section{SiMULATION RESULTS AND ANALYSIS}

\section{A. Test System 1: Indian Utility System}

The suggested technique is analyzed using an Indian utility system with six generators. Fuel rate and emission constants, lower and upper limitation,s and transmission loss coefficient matrix are extracted from [20]. For the simplification of the multi-objective problem, only $N O_{x}$ emission is considered. Also, the valve-point effects aren't considered for the problem. Simulation results are extracted using the power demand of 900MW. The algorithms were applied utilizing MATLAB programming language. During the simulation process, the compromise factor alpha takes values from 0 to 1 . The optimization results with different alpha values are specified in Table I. These simulation results are compared with [23] in Table II. The variation of total fuel cost with total emission is shown in Figure 2. The best compromise solution can be obtained from the resultant graph.

TABLE I. OPTIMIZATION RESULTS ON AN INDIAN UTILITY SYSTEM

\begin{tabular}{|c|c|c|c|c|}
\hline \multirow{2}{*}{$\begin{array}{c}\text { Test } \\
\text { system }\end{array}$} & $\begin{array}{c}\text { Control } \\
\text { variables }\end{array}$ & $\begin{array}{c}\text { PL } \\
(\mathbf{M W})\end{array}$ & $\begin{array}{c}\text { Total fuel } \\
\text { cost } \mathbf{( \$ / \mathbf { h r } )}\end{array}$ & $\begin{array}{c}\text { Total emissions } \\
\mathbf{( k g} / \mathbf{h r})\end{array}$ \\
\hline \multirow{3}{*}{$\begin{array}{c}\text { IEEE } \\
\text { 30 Bus } \\
\text { system }\end{array}$} & $\begin{array}{c}\mathrm{PD}=200 \mathrm{MW}, \\
\alpha=0\end{array}$ & 2.8283 & 545.2791 & 210.6876 \\
\cline { 2 - 5 } & $\begin{array}{c}\mathrm{PD}=200 \mathrm{MW}, \\
\alpha=0.5\end{array}$ & 3.5697 & 526.7653 & 217.5804 \\
\cline { 2 - 5 } & $\begin{array}{c}\mathrm{PD}=200 \mathrm{MW}, \\
\alpha=1\end{array}$ & 4.4955 & 518.5650 & 235.4381 \\
\hline
\end{tabular}


TABLE II. EED RESULTS WITH OF 900MW DEMAND

\begin{tabular}{|c|c|c|}
\hline Parameters & \multicolumn{2}{|c|}{ SR-PSO } \\
\hline$P_{G_{i}}$ & $\begin{array}{c}\text { Economic } \\
\text { dispatch (MW) }\end{array}$ & $\begin{array}{c}\text { Emission } \\
\text { dispatch } \mathbf{( M W )}\end{array}$ \\
\hline $\mathbf{1}$ & 120.5966 & 86.9897 \\
\hline $\mathbf{2}$ & 35.2975 & 30.5767 \\
\hline $\mathbf{3}$ & 16.6013 & 22.9873 \\
\hline $\mathbf{4}$ & 10.0000 & 20.6892 \\
\hline $\mathbf{5}$ & 10.0000 & 20.4620 \\
\hline $\mathbf{6}$ & 12.0000 & 21.1235 \\
\hline PL (MW) & 4.4955 & 2.8283 \\
\hline Cost (\$/hr) & 518.5650 & 545.2791 \\
\hline Emissions (kg/hr) & 235.4381 & 210.6876 \\
\hline
\end{tabular}

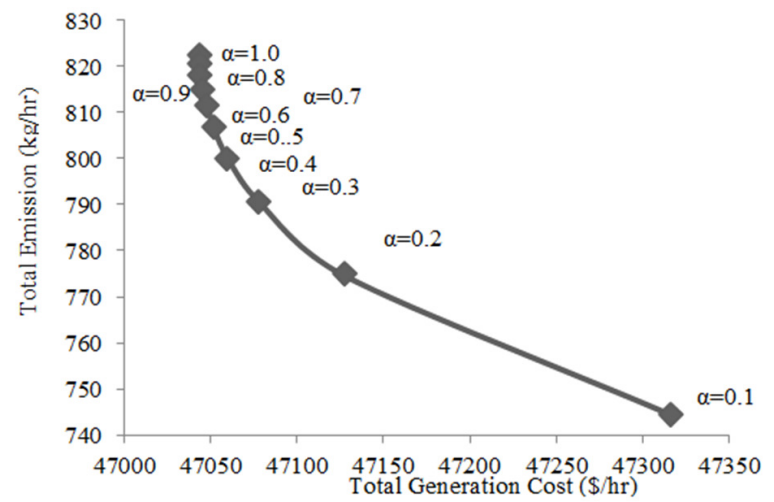

Fig. 2. Variation of generation cost with emission for different values of $\alpha$

\section{B. Test System 2: IEEE 30-Bus System}

This system has 6 generators and transmission losses are taken into consideration. The valve-point effects are not considered. Fuel and emission rate constants along with various inequality power constraints are taken from [19]. The simulation results are described using 200MW power demand. Table III shows the ideal solution of SR-PSO. The economic and emission dispatch results are shown in Table IV using compromise factor $\alpha$ as 1 and 0 respectively. The variation of total fuel rate with the total pollutant is definitely calculated with different values of compromise factors. The variation is plotted in Figure 3 and the best solution with the least value of fuel rate and pollutant can be found out from the graph.

TABLE III. OPTIMIZATION RESULTS OF THE IEEE 30 BUS SYSTEM

\begin{tabular}{|c|c|c|c|c|}
\hline \multirow{2}{*}{$\begin{array}{c}\text { Test } \\
\text { system }\end{array}$} & \multirow{2}{*}{$\begin{array}{c}\text { Control } \\
\text { variables }\end{array}$} & $\begin{array}{c}\text { PL } \\
(\mathbf{M W})\end{array}$ & $\begin{array}{c}\text { Total fuel } \\
\text { cost }(\mathbf{S} / \mathbf{h r})\end{array}$ & $\begin{array}{c}\text { Total emissions } \\
\mathbf{( k g} / \mathbf{h r})\end{array}$ \\
\hline \multirow{3}{*}{$\begin{array}{c}\text { IEEE } \\
\text { 30 B us } \\
\text { system }\end{array}$} & $\begin{array}{c}\mathrm{PD}=200 \mathrm{MW}, \\
\alpha=0\end{array}$ & 2.8283 & 545.2791 & 210.6876 \\
\cline { 2 - 5 } & $\begin{array}{c}\mathrm{PD}=200 \mathrm{MW}, \\
\alpha=0.5\end{array}$ & 3.5697 & 526.7653 & 217.5804 \\
\cline { 2 - 5 } & $\begin{array}{c}\mathrm{PD}=200 \mathrm{MW}, \\
\alpha=1\end{array}$ & 4.4955 & 518.5650 & 235.4381 \\
\hline
\end{tabular}

\section{Test System 3: IEEE 57-Bus System}

This system has 7 generators and 42 loads connected in various buses. The entire load demand is $1250.8 \mathrm{MW}$ and 336.4MVAR, without line limitations. Analysis has been conducted without considering transmission losses. Fuel and emission rate constants alongside various inequality power constraints are taken from [21]. Table $\mathrm{V}$ shows the optimization results for 3 different values of $\alpha$. The EED result is shown in Table VI. The variation of total fuel cost with total emissions is shown in Figure 4 for various values of $\alpha$. The best compromise solution can be obtained with the best execution time from the resultant graph. The simulation results of SRPSO are described using the power demand of $900 \mathrm{MW}$.

TABLE IV. EED RESULTS WITH 200MW DEMAND

\begin{tabular}{|c|c|c|}
\hline Parameters & \multicolumn{2}{|c|}{ SR-PSO } \\
\hline$P_{G_{i}}$ & $\begin{array}{c}\text { Economic dispatch } \\
\text { (MW) }\end{array}$ & $\begin{array}{c}\text { Emission dispatch } \\
\text { (MW) }\end{array}$ \\
\hline $\mathbf{1}$ & 120.5966 & 86.9897 \\
\hline $\mathbf{2}$ & 35.2975 & 30.5767 \\
\hline $\mathbf{3}$ & 16.6013 & 22.9873 \\
\hline $\mathbf{4}$ & 10.0000 & 20.6892 \\
\hline $\mathbf{5}$ & 10.0000 & 20.4620 \\
\hline $\mathbf{6}$ & 12.0000 & 21.1235 \\
\hline PL (MW) & 4.4955 & 2.8283 \\
\hline Cost (\$/hr) & 518.5650 & 545.2791 \\
\hline Emission(kg/hr) & 235.4381 & 210.6876 \\
\hline
\end{tabular}

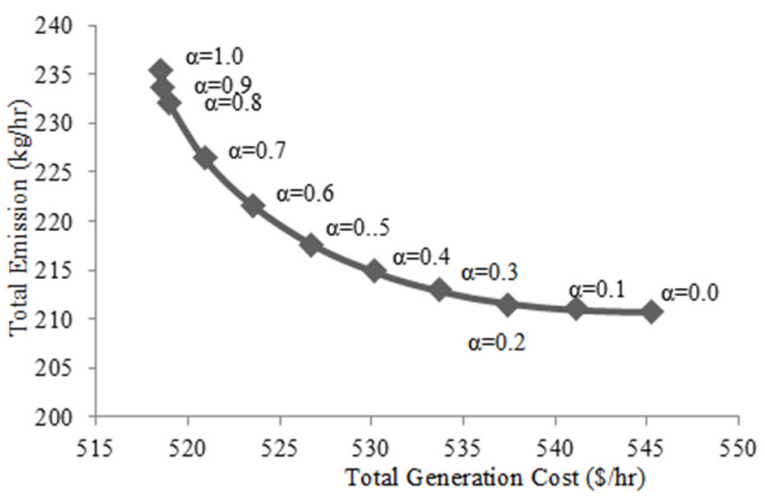

Fig. 3. Variation of generation cost with emission for different values of $\alpha$

TABLE V. OPTIMIZATION RESULTS OF THE IEEE 57 BUS SYSTEM

\begin{tabular}{|c|c|c|c|}
\hline \multirow[b]{2}{*}{ Test system } & \multirow{2}{*}{$\begin{array}{c}\text { Control } \\
\text { variables }\end{array}$} & \multicolumn{2}{|c|}{ SR-PSO } \\
\hline & & $\begin{array}{l}\text { Total fuel } \\
\text { cost }(\$ / h r)\end{array}$ & $\begin{array}{c}\text { Total emission } \\
(\mathrm{kg} / \mathrm{hr})\end{array}$ \\
\hline \multirow{3}{*}{$\begin{array}{c}\text { IEEE } 57 \text { Bus } \\
\text { system }\end{array}$} & $\begin{array}{c}\mathrm{P}_{\mathrm{D}}=900 \mathrm{MW}, \\
\alpha=0\end{array}$ & 5086.2578 & 1667.0086 \\
\hline & $\begin{array}{c}\mathrm{P}_{\mathrm{D}}=900 \mathrm{MW}, \\
\alpha=0.5\end{array}$ & 2717.3640 & 2595.5687 \\
\hline & $\begin{array}{c}\mathrm{P}_{\mathrm{D}}=900 \mathrm{MW}, \\
\alpha=1\end{array}$ & 2534.5068 & 3114.8429 \\
\hline
\end{tabular}

TABLE VI. EED RESULTS WITH 900MW DEMAND

\begin{tabular}{|c|c|c|}
\hline Parameters & \multicolumn{2}{|c|}{ SR-PSO } \\
\hline$P_{G_{i}}$ & $\begin{array}{c}\text { Economic } \\
\text { dispatch } \mathbf{( M W )}\end{array}$ & $\begin{array}{c}\text { Emission } \\
\text { dispatch } \mathbf{( M W )}\end{array}$ \\
\hline $\mathbf{1}$ & 384.5697 & 188.4421 \\
\hline $\mathbf{2}$ & 10.0000 & 93.8984 \\
\hline $\mathbf{3}$ & 20.0000 & 104.1802 \\
\hline $\mathbf{4}$ & 10.0000 & 94.1156 \\
\hline $\mathbf{5}$ & 341.1844 & 173.7787 \\
\hline $\mathbf{6}$ & 10.0000 & 93.9535 \\
\hline $\mathbf{7}$ & 124.2458 & 151.6316 \\
\hline Cost (\$/hr) & 2534.5068 & 5086.2578 \\
\hline Emission (kg/hr) & 3114.8429 & 1667.0086 \\
\hline
\end{tabular}




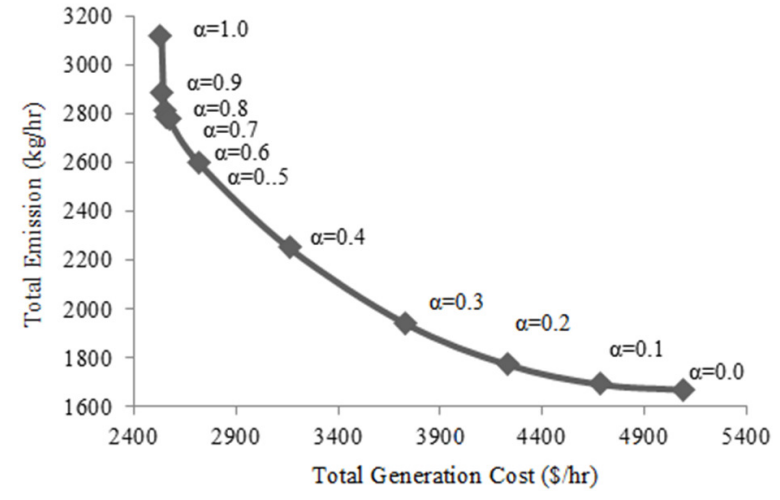

Fig. 4. Variation of generation cost with emission for different values of $\alpha$

\section{Test System 4: IEEE 118-Bus System}

Simulations were run on a typical 118-bus system. This is one of the largest power systems with 14 generating units. The fuel and emission rate constants, alongside various inequality power constraints were taken from [19]. The optimization results are listed in Table VII. Economic and emission dispatch results are demonstrated in Table VIII. The system load demand is 950MW. Total fuel cost variation and total emissions are given in Figure 5.

TABLE VII. OPTIMIZATION RESULTS OF THE IEEE 118 BUS SYSTEM

\begin{tabular}{|c|c|c|c|c|}
\hline \multirow[b]{2}{*}{$\begin{array}{c}\text { Test } \\
\text { system }\end{array}$} & \multirow[b]{2}{*}{$\begin{array}{c}\text { Control } \\
\text { variables }\end{array}$} & \multicolumn{3}{|c|}{ SR-PSO } \\
\hline & & $\begin{array}{c}\text { PL } \\
(\mathbf{M W})\end{array}$ & $\begin{array}{l}\text { Total fuel } \\
\text { cost }(\$ / h r)\end{array}$ & $\begin{array}{c}\text { Total emissions } \\
\text { (kg/hr) }\end{array}$ \\
\hline \multirow{3}{*}{$\begin{array}{c}\text { IEEE } 118 \\
\text { Bus system }\end{array}$} & $\begin{array}{c}\mathrm{PD}=950 \mathrm{MW}, \\
\alpha=0\end{array}$ & 7.6657 & 4594.7261 & 23.4037 \\
\hline & $\begin{array}{c}\mathrm{PD}=950 \mathrm{MW}, \\
\alpha=0.5\end{array}$ & 7.3835 & 4441.8930 & 91.2697 \\
\hline & $\begin{array}{c}\mathrm{PD}=950 \mathrm{MW}, \\
\alpha=1\end{array}$ & 10.0603 & 4347.8062 & 398.2422 \\
\hline
\end{tabular}

TABLE VIII. EED RESULTS WITH 950MW DEMAND

\begin{tabular}{|c|c|c|}
\hline Parameters & \multicolumn{2}{|c|}{ SR-PSO } \\
\hline$P_{G_{i}}$ & $\begin{array}{c}\text { Economic dispatch } \\
\text { (MW) }\end{array}$ & $\begin{array}{c}\text { Emission } \\
\text { dispatch } \mathbf{( M W )}\end{array}$ \\
\hline $\mathbf{1}$ & 102.6883 & 70.5071 \\
\hline $\mathbf{2}$ & 90.7391 & 50.0000 \\
\hline $\mathbf{3}$ & 50.0000 & 77.7310 \\
\hline $\mathbf{4}$ & 50.0000 & 88.6522 \\
\hline $\mathbf{5}$ & 50.0000 & 67.6157 \\
\hline $\mathbf{6}$ & 50.0020 & 50.0007 \\
\hline $\mathbf{7}$ & 50.0000 & 73.4310 \\
\hline $\mathbf{8}$ & 50.0002 & 72.3253 \\
\hline $\mathbf{9}$ & 63.2259 & 73.2658 \\
\hline $\mathbf{1 0}$ & 63.1861 & 89.5837 \\
\hline $\mathbf{1 1}$ & 62.8433 & 50.0000 \\
\hline $\mathbf{1 2}$ & 177.3753 & 72.4813 \\
\hline $\mathbf{1 3}$ & 50.0000 & 72.0719 \\
\hline $\mathbf{1 4}$ & 50.0000 & 50.0000 \\
\hline PL (MW) & 10.0603 & 7.6657 \\
\hline Cost (\$/hr) & 4347.8062 & 4594.7261 \\
\hline Emission (kg/hr) & 398.2422 & 23.4037 \\
\hline
\end{tabular}

\section{CONCLUSION}

SR-PSO analysis was conducted in order to resolve the EED problem for the above mentioned power systems. Power dispatch is planned into two objective functions, diminishing concurrently total operating cost and pollutant emissions. Two objectives converge into one function, by utilizing a mathematic modeling method. Optimum values of required variables are obtained for several loading conditions for IEEE systems having 30, 57 and 118 buses and an Indian Utility system with six generators. The result satisfies all the chosen constraints. The comparison shows that the proposed approach has competitive performance in resolution conditions and computation time. The proposed SR-PSO is robust, efficient and simple. This paper does not impose any constraints on the number of objectives and may be extended to incorporate more objectives, by utilizing various algorithms.

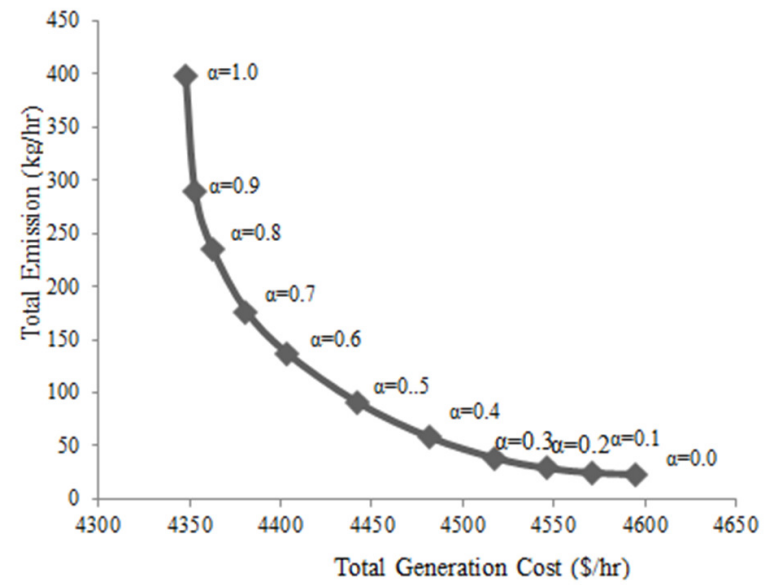

Fig. 5. Variation of generation cost with emission for different values of $\alpha$

\section{REFERENCES}

[1] V. K. Jadoun, N. Gupta, K. R. Niazi, A. Swarnkar, "Modulated particle swarm optimization for economic emission dispatch", International Journal of Electrical Power and Energy Systems, Vol. 73, pp. 80-88, 2015

[2] L. Wang, C. Singh, "Environmental/economic power dispatch using a fuzzified multi-objective particle swarm optimization algorithm", Electrical Power Systems Research, Vol. 77, No. 12, pp. 1654-1664, 2007

[3] M. A. Abido, "Environmental/Economic power dispatch using multiobjective evolutionary algorithms", 2003 IEEE Power Engineering Society General Meeting, Toronto, Canada, July 13-17, 2003

[4] D. Aydin, S. Ozyon, C. Yasar, T. Liao, "Artificial bee colony algorithm with dynamic population size to combined economic and emission dispatch problem", International Journal of Electrical Power and Energy Systems, Vol. 54, pp. 144-153, 2014

[5] P. K. Hota, A. K. Barisal, R. Chakrabarti, "Economic emission load diapatch through fuzzy based bacterial foraging algorithm", International Journal of Electrical Power and Energy Systems, Vol. 32, No. 7, pp. 794-803, 2010

[6] D. W. Gong, Y. Zhang, C. L. Qi, "Environmental/economic power dispatch using a hybrid multi-objective optimization algorithm", International Journal of Electrical Power and Energy Systems, Vol. 32, No. 6, pp. 607-614, 2010

[7] M. A. Abido, "Multiobjective particle swarm optimization for environmental/economic dispatch problem", Electrical Power Systems Research, Vol. 79, No. 7, pp. 1105-1113, 2009

[8] A. Y. Abdelaziz, E. S. Ali, S. M. Abd Elazim, "Combined economic and emission dispatch solution using Flower Pollination Algorithm", 
International Journal of Electrical Power and Energy Systems, Vol. 80, pp. 264-274, 2016

[9] L. Benasla, A. Belmadani, M. Rahli, "Spiral Optimization Algorithm for solving Combined Economic and Emission Dispatch", International Journal of Electrical Power and Energy Systems, Vol. 62, pp. 163-174, 2014

[10] L. H. Wu, Y. N. Wang, X. F. Yuvan, S. W. Zhou, "Environmental/economic power dispatch problem using multi-objective differential evolution algorithm", Electrical Power Systems Research, Vol. 80, No. 9, pp. 1171-1181, 2010

[11] L. Wang, C. Singh, "Stochastic economic emission load dispatch through a modified particle swarm optimization algorithm", Electrical Power Systems Research, Vol. 78, pp. 1466-1476, 2008

[12] M. A. Abido, "A niched Pareto genetic algorithm for multiobjective environmental/economic dispatch", International Journal of Electrical Power and Energy Systems, Vol. 25, No. 2, pp. 97-105, 2003

[13] A. Y. Abdelaziz, E. S. Ali, S. M. Abd Elazim,"Flower pollination algorithm to solve combined economic and emission dispatch problems", Engineering Science and Technology, an International Journal, Vol. 19, No. 2, pp. 980-990, 2016

[14] F. Chen, G. H. Huang, Y. R. Fan, R. F. Liao, "A nonlinear fractional programming approach for environmental-economic power dispatch", International Journal of Electrical Power and Energy Systems, Vol. 78, pp. 463-469, 2016

[15] S. Dhanalakshmi, S. Kannan, K. Mahadevan, S. Baskar, "Application of modified NSGA-II algorithm to Combined Economic and Emission Dispatch problem", International Journal of Electrical Power and Energy Systems, Vol. 33, No. 9, pp. 992-1002, 2011

[16] A. A. Abou El Ela, M. A. Abido, S. R. Spea, "Differential evolution algorithm for emission constrained economic power dispatch problem", Electric Power Systems Research, Vol. 80, No. 10, pp. 1286-1292, 2010

[17] T. Niknam, H. D. Mojarrad, B. B. Firouzi, "A new optimization algorithm for multi-objective Economic/Emission Dispatch", International Journal of Electrical Power and Energy Systems, Vol. 46, pp. 283-293, 2013

[18] Y. Zhang, D. W. Gong, Z. Ding, "A bare-bones multi-objective particle swarm optimization algorithm for environmental/economic dispatch", Information Sciences, Vol. 192, pp. 213-227, 2012

[19] M. Modiri-Delshad, N. Abd Rahim, "Multi-objective backtracking search algorithm for economic emission dispatch problem", Applied Soft Computing, Vol. 40, pp. 476-494, 2016

[20] M. Basu, "Economic environmental dispatch using multi-objective differential evolution”, Applied Soft Computing, Vol. 11, No. 2, pp. 2845-2853, 2011

[21] S. P. Karthikeyan, K. Palanichami, C. Rani, I. J. Raglend, D. P. Kothari, "Security Constrained Unit Commitment Problem with Operational, Power Flow and Environmental Constraints", WSEAS Transactions on Power Systems, Vol.4, pp. 53-66, 2009

[22] B. Hadji, B. Mahdad, K. Srairi, N. Mancer, "Multi-objective PSOTVAC for Environmental/Economic Dispatch Problem", Energy Procedia, Vol. 74, pp. 102-111, 2015

[23] J. Cai, X. Ma, Q. Li, L. Li, H. Peng, "A multi-objective chaotic ant swarm optimization for environmental/economic dispatch", International Journal of Electrical Power and Energy Systems, Vol. 32, No. 5, pp. 337-344, 2010

[24] L. Bayon, J. M. Grau, M. .M. Ruiz, P. M. Suarez, "The exact solution of the environmental/economic dispatch problem", IEEE Transactions on Power Systems, Vol 27, No. 2, pp. 723-731, 2012

[25] B. Y. Qu, Y. S. Zhu, Y. C. Jiao, M. Y. Wu, P. N. Suganthan, J. J. Liang, "A survey on multi-objective evolutionary algorithms for the solution of the environmental/economic dispatch problems", Swarm and Evolutionary Computation, Vol. 38, pp. 1-11, 2018

[26] W. T. Elsayed, Y. G. Hegazy, M. S. El-bages, F. M. Bendary, "Improved random drift particle swarm optimization with self-adaptive mechanism for solving the power economic dispatch problem", IEEE Transactions on Industrial Informatics, Vol. 13, No. 3, pp. 1017-1026, 2017
[27] Q. Qin, S. Cheng, X. Chu, X. Lei, Y. Shi, “Solving non-convex/nonsmooth economic load dispatch problems via an enhanced particle swarm optimization", Applied Soft Computing, Vol. 59, pp. 229-242, 2017

[28] B. R. Adarsh, T. Raghunathan, T. Jayabarathi, X. S. Yang, "Economic dispatch using chaotic bat algorithm", Energy, Vol. 96, pp. 666-675, 2016

[29] D. Zou, S. Li, G. G. Wang, Z. Li, H. Ouyang, “An improved differential evolution algorithm for the economic load dispatch problems with or without valve-point effects", Applied Energy, Vol. 181, pp. 375-390, 2016

[30] M. P. Wachowiak, M. C. Timson, D. J. Du Val, "Adaptive particle swarm optimization with heterogeneous multicore parallelism and GPU acceleration", IEEE Transactions on Parallel Distributed Systems, Vol. 28, No. 10, pp. 2784-2793, 2017

[31] Y V. K. Reddy, M D. Reddy, "Solution of Multi Objective Environmental Economic Dispatch by Grey Wolf Optimization Algorithm", International Journal of Intelligent Systems and Applications, Vol. 7, No. 1, pp. 34-41, 2019

[32] M. Jevtic, N. Jovanovic, J. Radosavljevic, D. Klimenta, "Moth swarm algorithm for solving combined economic and emission dispatch problem", Elektronika ir Elektrotechnika, Vol. 23, No. 5, pp. 21-28, 2017

[33] H. Wang, J. H. Yi, "An improved optimization method based on krill herd and artificial bee colony with information exchange", Memetic Computing, Vol. 10, No. 2, pp. 177-198, 2018

[34] M. Neyestani, M. Hatami, S. Hesari, "Combined heat and power economic dispatch problem using advanced modified particle swarm optimization", Journal of Renewable and Sustainable Energy, Vol. 11, No. 1, 2019

[35] X. Chen, B. Xu, C. Mei, Y. Ding, K. Li, "Teaching-learning-based artificial bee colony for solar photovoltaic parameter estimation", Applied Energy, Vol. 212, pp. 1578-1588, 2018 